\title{
BENJAMIN \\ CONSTANT, \\ LA FRAGILIDAD \\ POLÍTICA
}

Lourdes Quintanilla*

\section{" $\mathrm{He}$ defendido durante cuarenta} años el mismo principio: la libertad", dice Constant al final de su vida. El principio ordenador por excelencia es el centro, punto de partida y de llegada. La circunferencia -la historia- gira sobre su núcleo en movimiento perpetuo. En el lenguaje simbólico constantiano, la chaîne tiende al principio y algún día se une y coincide con él para volver a empezar. Se fundamenta en las correspondencias que existen entre todos los ámbitos de la realidad, que los liga unos a otros y se extienden desde el orden natural, tomado en su conjunto, al orden espiritual o ético si se prefiere. En virtud de estas correspondencias, la naturaleza no es en sí misma más que un símbolo, un soporte para elevarnos en el espacio de la libertad.

La chaîne es, al mismo tiempo, el símbolo que presenta la unidad pasado/presente y el que rompe la supuesta autonomía de una esfera de acción. Es también símbolo del cosmos en el ir y venir por el delicado equilibrio entre el orden y el caos. La política, siempre amenaza$\mathrm{da}$, puede perderse con cualquier movimiento en falso y su significado puede de pronto oscurecerse, de allí su fragilidad.

* Facultad de Ciencias Políticas y Sociales, UNAM. 


\section{LOURDES QUINTANILLA}

Sólo aquellos que mediante la razón -el sacrificio-pueden superar las limitaciones y reconocerlas como impedimentos que son para el deslizamiento eficaz de la chaîne, tienen la capacidad, y deben actuar en consecuencia. Los principios son excelsos y no se demuestran. Se percibe directamente su verdad porque la especificidad del individuo constantiano está en su libertad y en la capacidad de sacrificio para luchar por ella día tras día hasta conquistarla. Si ha brillado esa luz es porque prevalecen rodeos y desvíos, pero no hay regreso. Luz en su sentido más profundo: solar, espiritual. Pero la luz perfecta es inimaginable sin la oscuridad; la luz puede abandonar su camino, su rumbo, se puede perder y sumergir en estadios inferiores. Hay que evitarlo valerosamente. La luz sin caminos unidireccionales, sin garantía de dominio, anclada en portadores siempre finitos, pero igualmente refulgentes que sacrifican y saben que la perfección es inalcanzable, pues ésta haría superflua la libertad.

Constant lucha con sus principios en medio de la azarosa vida de Francia. El centro permanece, la rueda gira. El hilo que sostiene los eslabones de la chaîne puede cortarse. Se preocupa entonces por las formas constitucionales que, frágiles como todo acuerdo humano, permitan la transmutación. Insiste, a lo largo de su actividad política, en los principios ordenadores de las relaciones entre los hombres en ese espacio social que antes se llamaba ciudad. Apasionada y seriamente se ocupa del derecho, porque está consciente de su responsabilidad en los asuntos de los hombres y se compromete en la contienda política de su tiempo, a convertir el poder legislativo en soberano dentro del precario equilibrio de fuerzas. Sabe que existen varias formas de derecho, no sólo la legalidad estatal, de ahí que defienda la multiplicidad en la unidad, los derechos anteriores al estado que no son un mero factum.

Como Montaigne, Constant sabe que las leyes se obedecen no porque sean justas sino porque son leyes y allí reside la fuerza mística de su autoridad; como Montesquieu, piensa en ese delicado juego de pesos y contrapesos que permite organizar el reino de lo social. Contra Rousseau y la subjetividad del yo colectivo, opone el individuo oscuro, 
que es al mismo tiempo plural, pues se encuentra inmerso en una colosal red de relaciones, lo cual no impide defender su sacrosanta libertad política, que no es una graciosa concesión del poder público sino el derecho de resistencia del ciudadano frente a la arbitrariedad de los poderes todos.

Stendhal advirtió hace ya muchos años que el despotismo se presenta como un gobierno normal, de ahí su peligro porque oculta un am̌o. Constant ya había reparado en el simulacro y lo puso en evidencia bajo el régimen napoleónico. También el Terror se invistió como un gobierno de la mayoría y camufló el hecho de que esa instancia política, que de hecho no pertenece a nadie pero en la cual todos se reconocen, estaba en manos del 'despotismo de la libertad'.

Muchas opiniones se han vertido sobre Constant. Tal vez sus contemporáneos advirtieron los matices, errores y limitaciones de su humana naturaleza mejor de lo que nosotros podemos hacerlo a la distancia. Las acusaciones, falsas o verdaderas, en realidad no interesan. El juicio -facultad humana por excelencia- no puede basarse sólo en abstracciones, requiere también del pensar y el sentir. Constant mantiene abierto el símbolo, ese antiguo fondo donde lo pasajero se borra y queda el sentido esencialmente sintético, punto de apoyo que despeja posibilidades de comprensión.

La política se acompaña siempre de un modelo 'ideal', de lo contrario se convierte en una mera gestión administrativa. Al mismo tiempo es empírica: verifica sobre los hechos, corrige y vuelve a corregir. Si no fuera así se mudaría en una abstracción. Aun cuando el modelo -la dimensión imaginaria- sea a largo plazo, la política tiene que manejar los diversos niveles de la realidad, que aparecen simultáneamente como en una escena teatral; la necesidad y el tiempo.

Constant participó activamente en la política armado con sus principios aplicables a todas las formas de gobierno, ya fuera monarquía o república, para que garantizaran el ejercicio de la libertad. Ello explica sus ires y venires y también su 'alianza' con Napoleón tras la aguda crítica al emperador. Fue acusado de oportunista por tirios y troyanos. Cabría preguntarse entonces ¿en qué consiste el oportunismo políti- 
co $?^{1}$ Constant defendió sus principios con y frente a Napoleón, lo que evidentemente no era fácil; con y frente a los borbones y los ultra, y también con amigos y enemigos de la classe intermédiaire. Desesperó, es cierto, pero como Ariosto siguió en la lucha hasta el fin.

El lenguaje de Constant es incisivo, no un mero objeto a la manera del positivismo decimonónico, que pretende reflejar como en un espejo la realidad social, que ya es historia. Permanece la imagen del individuo constantiano, que no es la de un espectador pasivo, ni soberano sometido y empírico. Es aquel que exige, defiende a ultranza y comunica su libertad y resistencia a la opresión. Vive intensamente en su espacio social, no obstante las dificultades que supone llegar a puerto. Pero en su fortaleza, en su centro, permanece activo mientras gira la rueda del mundo.

Los principios toman tierra y se enfrentan a la precariedad, al azar y a la necesidad en medio de la historia que se vive y se hereda. El genuino pensamiento político pone a prueba sus principios en situaciones concretas y cambiantes. Las convenciones son factices, pero de ellas depende la continuidad y la conservación misma de la nación. Lejos del torrente, pero en la cresta de la ola, Constant forja los medios - normas constitucionales- para tratar de alcanzar el fin supremo y último: la libertad. Analiza cuidadosamente la legitimidad-convención factice-, cuya fuerza misteriosa exorciza el miedo y, paradójicamente, se realiza en el tiempo, no en las aguas pantanosas del origen que no existe y se inventa a posteriori. Al recurrir al poder neutro -ficción, ser abstracto, no humano, que está en todas partes y en ninguna, irresponsable como siempre-mantiene lo sagrado en el ámbito de la política. La consagración del poder es ahora constitucional, el derecho

${ }^{1}$ Nadie como Shakespeare nos puede dar una abreviada lección. En Hamlet (III, 2) se entabla un diálogo ejemplar entre el príncipe de Dinamarca y Polonio. El primero dice: "Veis aquella nube cuya forma es semejante a un camello", y Polonio: "parece un camello realmente". Hamlet: "Yo creo que parece una comadreja". Respuesta: "Tiene el dorso de una comadreja". El príncipe: "O de una ballena". "Exacto, de una ballena", asiente su interlocutor. 
divino de los reyes se ha vuelto laico y está grabado con letras de oro en las nuevas tablas de la ley.

Comprender, no explicar. Nada está aislado, ¡tout se tient! ${ }^{2}$ El análisis constantiano se convierte en precursor de la antropología política al mirar el todo con los lazos invisibles que lo conforman; analogías y correspondencias insospechadas. Su mirada se mueve en diversos planos, su reflexión busca la unidad en la rica y variada multiplicidad que la constituye, su concepción del tiempo simultáneo le permite ir y venir por el antiguo presente mientras observa atentamente los acontecimientos y prepara el porvenir. Por ello, puede forjar principios y pretender que sean verdades -no vanas teorías-, faros que factiblemente iluminen la acción, dirijan la marcha y transmitan evidencias que garanticen la continuidad.

En la práctica parlamentaria y en la prensa, Constant hizo gala de su lucidez y de su pasión. Sus principios se enfrentaban a la realidad sinuosa y compleja cuando parecía posible volver al antiguo régimen, pero lo nuevo siempre se construye sobre lo viejo. Imposible inventar otro país. Como Talleyrand, su ilustre contemporáneo, contemplaba el panorama, no los retrasos accidentales. Se jugaba el destino de Francia.

Mesura, razón, equidad han sido motivo de preocupación a lo largo de la historia, pero su triunfo es impensable sin sus opuestos: la desmesura, el error, la desigualdad. Las pasiones, los instintos, el accidente -como señaló Tocqueville- tienen un papel importante aunque es difícil precisarlo. Sólo cuando la política actúa entre hombres libres

${ }^{2}$ Tal y como explica Lefort, "la política no es un sector particular de la vida social. Ella implica, por el contrario, la noción de un principio o un conjunto de principios generadores de las relaciones que los hombres mantienen entre ellos mismos y con el mundo": Claude Lefort, Essais sur le politique XIX'-XXe siècles, 1986, Paris, Editions du Seuil, p. 8. Lefort busca la impronta de la política en los hechos, los actos, las representaciones, las relaciones en una forma de sociedad y su dimensión simbólica. Constant parte del ;tout se tient!, donde cuando un eslabón se rompe amenaza al conjunto. 


\section{LOURDES QUINTANILLA}

los límites se establecen por añadidura, como quería Constant. El sueño parece irrealizable, pero hay que vivir como si fuera posible lo imposible.

A través de las reflexiones constantianas, algunas respuestas se dibujan para las preocupaciones actuales, pero las preguntas siguen formuladas, inevitablemente, porque no hay nada definitivo. Preguntar es la tarea, hacer un alto en el camino, ¿qué tenemos hoy?: ¡a cada siglo sus problemas!, solía decir. Igual que a principios del siglo XIX, el caos parece preceder al impulso -dimensión incalculable- y, por lo tanto, azaroso. No se perfila todavía con claridad el espíritu de la nueva época. Lo único seguro es la inseguridad y en ella tenemos que pensar la libertad de los modernos.

Benjamin Constant es un viejo conocido en México. José María Luis Mora era su atento lector; Lucas Alamán lo conoció en París y seguramente se interesó por ese liberalismo conservador atento a no lastimar el tiempo. E1 poder neutro se estableció en México en 1836. Mariano Otero -al decir de Jesús Reyes Heroles- siguió atentamente el escrito sobre la perfectibilidad y debió haberle llamado la atención la dignidad del Congreso en la obra constantiana.

No se ha hecho todavía un estudio sobre la influencia de Constant en México, pero es indudable que un pensador representante de esa difícil transición entre la revolución y la monarquía de Luis Felipe, iluminaba la turbulenta historia mexicana de aquellos años. La experiencia francesa era el espejo. Convidemos a Constant, otra vez, al escenario 'posmoderno'.

Maestro para quienes se ocupan del análisis del discurso político, Constant pone en evidencia los simulacros, critica radicalmente el lenguaje de los poderosos y entonces el rey va desnudo. La opinión razonable desbarata eufemismos y deja mudos a quienes pretenden cubrir las apariencias con una retórica irracional.

Constant publicista estudia, confronta, busca asesoría en temas dificiles y exhibe a quienes, a la derecha o a la izquierda, sólo pretenden el consenso 'popular' sin la responsabilidad indispensable de un poder legislativo digno de este nombre. Todos los poderes pasan por el 
BENJAMIN CONSTANT

cedazo de la crítica, los abusos se denuncian, los límites se establecen día tras día.

En el reducido espacio donde se juega la lucha liberal -hoy se llama democrática-, razonar es esencial. Quien no comprenda los discursos que no se sienta afligido: son incomprensibles. Hay verdades que rebasan los conceptos y han salido directamente del corazón de la propia historia. No es un problema de teorías, sino de sensibilidad y olfato político mientras los principios dirigen la acción. Jamás se puede permitir una arbitrariedad, pues una sucede a la otra.

Las garantías -normas constitucionales-no son perfectas. El estado de derecho que soñaba Constant y contribuyó a fundar, sólo se puede alcanzar en la lucha cotidiana, y no se establece de una vez y para siempre. Multiplicidad de leyes perturban el orden. En el edificio constantiano, al igual que para los liberales de su tiempo, únicamente los ciudadanos activos tenían derecho a la representación, pero el voto popular, por importante que fuera, no garantizaba la voluntad general. Una nación es más que un resultado electoral y si no puede pedir cuentas a sus representantes coloca otro poder sobre sus hombros. Constant se detiene largamente en las asambleas representativas que deben ser animadas, pero razonables y con límites precisos.

La convención legitimadora y su 'fuerza misteriosa' va y viene y, sin embargo, sólo legitima el tiempo. Tal parece que el poder necesita un aura y en ella reside su verdadera fuerza. Constant pensaba que era difícil rodearse de majestad en la república. Tiene razón : si cualquiera puede representar, la representación pierde su encanto. La forma de gobierno se puede modificar en una convención y permitir la crítica implacable a los ministros responsables, mientras un poder muy por encima de ellos preserva la nación. No es una persona, un rey o un iluminado, es un poder abstracto más allá de la representación.

Lo sagrado ha acompañado al poder a lo largo de la historia. Un sustrato de realidad oscuro y secreto, un aura, una sombra parecen dar sentido a su existencia. Sin aura, el poder es cuestionable y se rompe la relación profunda con los gobernados. El peligro de que el aura sea muy intensa se remedia con la constitución, mientras la libertad perte- 
LOURDES QUINTANILLA

nece al individuo consciente de su poder y no dispuesto a ceder sus reservas de soberanía.

El poder abstracto da testimonio de sí y mantiene el orden, pero, a la vez, se diferencia de él. Constant construye el edificio con reglas precisas y el poder neutro vigila. No es un ejercicio inútil reflexionar sobre el tema: las sociedades modernas también inventan para encubrir una realidad que duele o humilla, y una vez 'muerto dios' poderes invisibles y lo sagrado permanecen. ¿Cómo pensar entonces la política? ${ }^{3}$

Las barreras infranqueables para todos los poderes se encuentran en los sacrosantos derechos individuales. La mirada de Constant se posa en el individuo soberano, centro de toda su reflexión. Si bien se pierde en la multitud, en la profunda soledad del yo, aturdido por la opinión y sin ninguna influencia en el conjunto, tiene derechos inalienables. Mientras el discurso los exalta, la realidad los niega.

En la Francia napoleónica el individuo yacía bajo el honor imperial; en la modernidad los ciudadanos activos yacen bajo una inmensa red burocrática y financiera que los envuelve. El poder, señala Foucault, se ejerce también horizontalmente, no en la simple dicotomía gobernantes/gobernados; penetra en todos los resquicios de la sociedad. El individuo defiende su fortaleza contra viento y marea o se abandona en medio de la tormenta. Es una tarea urgente poner en evidencia el simulacro, de lo contrario es inútil hablar de democracia.

Interés especial merece la concepción constantiana del tiempo simultáneo. Vivimos en un culto al presente delirante, se ha borrado de un plumazo el antiguo presente, no obstante que, para bien o para mal, heredamos la historia. Los discursos la maquillan, hay que quitarle las

3 "La paradoja es que toda la aventura que se juega con la formulación de una nueva idea de estado, de pueblo, de nación, de humanidad, tiene sus raíces en el pasado." A pesar de la ruptura entre religión y política, hay una dificultad, sin duda, para evitar la dimensión imaginaria de la primera. Lefort se pregunta: "¿no será un problema para el pensamiento político y filosófico asumir sin disfraz lo trágico de la condición moderna?" Véase Claude Lefort, "Permanence du théologico-politique?", op. cit., p. 295-300. 
máscaras. La ficción cubre la historia mexicana desde sus inicios: quiso ser liberal y es borbónica; quiso ser federalista y la tan ansiada unidad en la multiplicidad sólo figura inscrita en las sucesivas constituciones.

La división de poderes es una bella promesa. Múltiples tiempos en el mosaico nacional, culturas que parecen haber permanecido en la Colonia, una minoría en la 'posmodernidad'. Las reformas borbónicas se suceden bajo el cielo liberal, la Revolución mexicana -hoy asunto de anticuarios- no cumplió sus metas de justicia social. Entramos desarmados al ciclo globalizador. Se ha lastimado al tiempo, diría Constant, las verdades intempestivas sólo pueden imponerse gradualmente al razonar.

No tenemos atrás el modelo griego para iluminar el presente; sí al despotismo como práctica. Se necesita la 'mano temblorosa' de Montesquieu. Prestarse a los cambios insensibles, aconsejaba Constant, aprender de los fracasos, porque hay semillas de libertad en la propia historia desde sus comienzos legendarios, que han brotado una y otra vez a lo largo del camino. Allí están para transmitirlas al presente, y son principios que han tejido la cadena mexicana entre antiguos y modernos.

México tiene sus clásicos y su cultura no está al margen de Occidente, pero la historia maquillada ha impedido la comprensión del tapiz tejido por amigos y enemigos, héroes y villanos. Difícil distinguir el bien y el mal, las luces y las sombras en el claroscuro. Pensar la historia no para extasiarse en los archivos, sino para recuperar los hilos que la conforman. Dejar atrás errores y prejuicios, someter a la crítica más radical instituciones del pasado y del presente es una responsabilidad política. No podemos dejar de atender las reformas prematuras, la estabilidad factice, los anacronismos desmesurados. Constant deja como herencia la crítica y no podemos eludirla.

La opinión conforma a las instituciones que deben modificarse de acuerdo con el lento transcurrir del tiempo, para evitar lo que ahora se ha dado en llamar ingobernabilidad. Las instituciones obsoletas son peligrosas para la conservación y el cambio, habría que reinventarlas, corregirlas una y otra vez y sentarlas en tierra firme. El tiempo político exige la correcta comunicación, porque si no se atenta contra el 'miste- 


\section{LOURDES QUINTANILLA}

rio de la autoridad'. Si el gobierno es débil se obliga a la arbitrariedad; con límites precisos y debidamente vigilado tiene que conducirse con prudencia y escuchar a la opinión. El arte de gobernar no se improvisa a voluntad; hay normas precisas para ejercerlo, pero no tiene derecho a lastimar al tiempo.

Nada se logra con la pasividad, parece decir Constant. Sólo la lucha apasionada y permanente haría posible los cambios insensibles. ¿Ilusiones revolucionarias en el progresismo? Tal vez. El mundo liberal que dibuja Constant tiene por actores principales a los individuos libres y soberanos porque la libertad no se delega, nadie la representa, es la única y verdadera propiedad. ${ }^{4} \mathrm{~A}$ mayor número de individuos concebidos a la manera constantiana, menor importancia de los poderes 'estacionarios'. El liberalismo no es un simple problema político. Si bien se mira es una cuestión social y cultural. La mirada recorre la inmensa telaraña que rodea al centro hacia el panorama concreto, más allá de la política. Ver, solamente ver.

La compleja relación entre política, moral y religión señalada en el análisis constantiano invita a reflexionar. No basta separar Estado e Iglesia, el respeto a las creencias -imponer una opinión es tiraníaconstituye la verdadera tolerancia. Hay que aprender a ser laicos y disfrutar del derecho a equivocarse. Un pueblo profundamente religioso por usos y costumbres, con pasiones exacerbadas que rayan en el fanatismo, se niega al discurso modernizador, y es su derecho. Siglos de religiones sacerdotales y de poderes arbitrarios unidos y desunidos cubren el paisaje mexicano. Si se quería pensar en la educación de un pueblo, era necesario abatir la miseria, una desgracia para Constant. ¿Por dónde empezar?

${ }^{4}$ Los derechos del hombre y del ciudadano, defendidos a ultranza por Constant, son principios generadores de democracia. Lefort pone en evidencia la dimensión simbólica de dichos derechos y hace reconocer que ella es constitutiva de la sociedad política. Véase Claude Lefort, "Droits de l'homme et politique", L'invention démocratique. Les limites de la domination totalitaire, 1981, París, Fayard. 
BENJAMIN CONSTANT

Se pueden separar política, moral y religión en el escritorio, pero la realidad es más compleja. Hoy se conjuga en todos los tiempos el verbo tolerar; pero la intolerancia es 'salvaje', señala Umberto Eco, se inicia desde la cuna y las bondades de la razón se muestran impotentes frente a ella. Migraciones o inmigraciones han puesto sobre el tapete la noción de identidad múltiple y compleja bajo la máscara del yo; no basta la 'fortaleza', ni los discursos teñidos de pluralismo; los derechos individuales tienen que respetarse en la práctica concreta, todos los días y a todas horas, pues son tan naturales, diría Constant, ni siquiera se discuten.

Límites y más límites para evitar la desmesura, pero el problema es tan viejo como el mundo. Por doquier normas, leyes y prohibiciones conforman a las sociedades antiguas y modernas. En las convenciones factices se inventaron monarquías y repúblicas, limitadas por la voluntad del pueblo o por derecho divino: Roma tenía un senado y cónsules plebeyos, y los límites se rompían una y otra vez. Marco Aurelio soñaba con un estado de derecho. Las asambleas representativas datan del medioevo. En plena modernidad volvieron a ellas Inglaterra y su 'gloriosa revolución', Francia, que inició la revolución con un clamor por los estados generales silenciados por el absolutismo, y España durante la invasión napoleónica, que recuperó las cortes vigentes desde el siglo XII. Todas ellas buscaron el presente en lo antiguo, reinventaron y transmitieron. Los límites se esgrimen en el quehacer político porque, desafortunadamente, no se establecen por decreto.

En el corazón de los escritos constantianos se encuentra la noción de límite. El acontecer mismo le llevó a insistir en ella, en medio del caos que rodeaba a las convenciones y cuando el optimismo ilustrado se perdía en las tinieblas. Había que construir, gradualmente, los peldaños que condujeran a la libertad. En este sentido, su reflexión tiene luz propia y representa la difícil transición posrevolucionaria.

1789 y sus secuelas modificaron las expectativas del siglo anterior con nuevas tareas y nuevos retos. Constant toma elementos del pasado y del presente para la conservación y el cambio. Se trataba de preservar Francia, nada más y nada menos. Se inventa en el camino, 
LOURDES QUINTANILLA

sobre la marcha, con la ayuda de los dioses y de los demonios. Un país no se dibuja en el escritorio. Constant siempre criticó la vanidad de quienes pretendían hacerlo y lanzaban consignas incendiarias irresponsablemente.

Los moderados construyen en medio de todos los radicalismos, operan con la ilusión de un orden, aunque su funcionamiento se nos escape. No se trata de explicar solamente, como pretende la fe secularizada, sino de comprender. El voluntarismo no edifica, pues no se puede partir de cero, cambiarlo todo.

La obediencia es misteriosa. La servidumbre voluntaria abate necesariamente el optimismo. Etienne de la Boëtie ya lo hacía notar en el siglo XVI: alegre y caprichosa, la opinión se pliega a los deseos de los poderosos, busca seguridad, no libertad. ¿Tenía razón Napoleón cuando afirmaba que Francia lo adoraba? Constant respondía que cuando sólo hay interés en el corazón del hombre todo puede ocurrir. El despotismo se sucede con la indiferencia, el egoísmo, el cálculo. Sin libertad política y la decisión de ejercerla plenamente, no puede haber un sistema liberal.

La Ilustración heredó del Renacimiento la idea del hombre como la medida de todas las cosas. El microcosmos de Marsilio Ficino, la dignidad humana del famoso discurso de Pico della Mirandola, la 'torre' de Montaigne. Voltaire, en el siglo XVIII, sólo quería 'cultivar su jardín'. El yo moderno se iba construyendo paso a paso con su arrogancia y sus limitaciones, y ponía el universo a su disposición. Todo parte del hombre y vuelve a él. ¡Vana ilusión! El caos nos envuelve, y conquistar un cosmos parece una tarea sobrehumana, aunque los hombres piensan alegremente que son autónomos.

Constant lo sabía muy bien, y atendió al todo concreto para tratar de fijar un orden y un destino en el tiempo simultáneo y las luces (el cosmos), no las tinieblas (el caos). Entre la luz y la sombra proseguiría la marcha, porque no hay nada definitivo. Al hacerlo sacralizó la libertad individual, al igual que muchos de sus contemporáneos. Baste recordar que el lema político-religioso con pretensiones absolutas y universales, 'Libertad, Igualdad y Fraternidad', se pronunció por pri- 
mera vez en el salón iluminista del conde de Saint Martin. Difícil explicar las nociones herméticas en la Ilustración, que posiblemente se transmitían en las sociedades secretas presentes en toda Europa.

El romanticismo acompañó a la Ilustración y colocó al hombre envuelto en el caos y en múltiples infinitos. La atmósfera de la época, aunada a la inestabilidad, hizo que muy pronto se perdiera la confianza en la razón y el yo perdió su carácter de rey del universo. Hablar del individuo puede ser un sinsentido si aparece como algo condicionado por la sociedad y por la historia.

¿Dónde queda entonces la libertad? Alrededor de ella han girado reflexiones de poetas, teólogos y filósofos durante milenios. La libertad también es misteriosa; hay que pensarla, sin embargo, como meta atemporal. Tal vez sólo con un íntimo sentimiento de su existencia se pueda preservar y merecer. Pero si los políticos la ofrecen, desconfiemos, porque ellos deben limitarse a cumplir con sus múltiples obligaciones y no a turbar el reposo de los privados.

En el fondo de la representación constantiana el microcosmos preserva su centro espiritual y exige respeto a todos los poderes estacionarios, los limita, para buscar su propio orden, su propio destino, no sin dificultades. Busca la luz para abatir sus propias tinieblas.

La física contemporánea cambia una y otra vez sus paradigmas. La flecha del tiempo irreversible puede encontrar durante su trayectoria bifurcaciones, estructuras disipativas, agujeros negros. Hace tiempo murió la concepción mecanicista, el determinismo es obsoleto. Con una metodología rigurosa y un lenguaje matemático preciso, el científico, con toda modestia, lanza preguntas al universo. No siempre obtiene respuestas, pero la búsqueda prosigue. Hoy la ciencia se hermana con la filosofía y piensa el lugar del hombre en el macrocosmos, igual que en la antigua Grecia, igual que en el Renacimiento.

La mirada de Constant puede ayudarnos a pensar nuestro mundo urgido de fantasía, sin descuidar la historia efectiva, pero lejos del torrente. La política parece haber quedado a la zaga de las grandes transformaciones mundiales. Lo nuevo se manifiesta en diversos signos. El tiempo político, en su lento transcurrir, se ha acelerado a niveles 
insospechados. El siglo de los grandes incendios, de las innovaciones tecnológicas, parece haber cambiado el rumb s de la historia, pero su continuidad no se rompe a voluntad.

Constant apelaba a la imaginación y a la juventud de los antiguos para arrancar a los modernos del bonheur doméstico. El arte de la política, la creación de convenciones factices acordes con el nuevo siglo, es el reto y la condición indispensable para proseguir la marcha. Porque entre el sueño y la historia se trata de construir puentes firmemente anclados en la tierra, entre el cielo y el abismo, entre la fortaleza y la precariedad. Los caminantes los atraviesan armados con los principios, cargados de derechos y deberes, y avanzan gracias al sacrificio -la razón-para depositar sus frutos en la otra orilla. Eterno peregrinar de la marcha progresiva. 